\title{
Volcanic Ash Cloud Observation using Ground-based Ka-band Radar and Near-Infrared Lidar Ceilometer during the Eyjafjallajökull eruption
}

\author{
Frank S. Marzano 1,2, Luigi Mereu 1,2, Mario Montopoli 1,2, \\ DOMENICO CIMINI ${ }^{3,2}$ AND GIOVANNI MARTUCCI ${ }^{4}$
}

\begin{abstract}
${ }^{1}$ DIET - Sapienza Università di Roma, Rome, Italy, ${ }^{2}$ Center of Excellence CETEMPS, University of L'Aquila, L'Aquila, Italy, ${ }^{3}$ IMAA, National Research Council (CNR) - Tito Scalo, Italy,

${ }^{4}$ National University of Ireland, Galway, Ireland (currently at MeteoSwiss, Switzerland)

*frank.marzano@uniroma1.it
\end{abstract}

\begin{abstract}
Active remote sensing techniques can probe volcanic ash plumes, but their sensitivity at a given distance depends upon the sensor transmitted power, wavelength and polarization capability. Building on a previous numerical study at centimeter wavelength, this work aims at i) simulating the distal ash particles polarimetric response of millimeter-wave radar and multi-wavelength optical lidar; ii) developing and applying a model-based statistical retrieval scheme using a multi-sensor approach. The microphysical-electromagnetic forward model of volcanic ash particle distribution, previously set up at microwaves, is extended to include non-spherical particle shapes, vesicular composition, silicate content and orientation phenomena for both millimeter and optical bands. Monte Carlo generation of radar and lidar signatures are driven by random variability of volcanic particle main parameters, using constraints from available data and experimental evidences. The considered case study is related to the ground-based observation of the Eyjafjallajökull (Iceland) volcanic ash plume on May 15, 2010, carried out by the Atmospheric Research Station at Mace Head (Ireland) with a 35-GHz Ka-band Doppler cloud radar and a 1064-nm ceilometer lidar. The detection and estimation of ash layer presence and composition is carried out using a Bayesian approach, which is trained by the Monte Carlo model-based dataset. Retrieval results are corroborated exploiting auxiliary data such as those from a ground-based microwave radiometer also positioned at Mace Head.
\end{abstract}

\section{INTRODUCTION}

$\mathrm{V}$ olcanoes are among most important natural sources of ash, which may influence meteo-climatological conditions on large scales modifying the Earth radiation budget [Graf et al., 2007]. Continuous monitoring of such phenomena is crucial for the initialization of ash dispersion models [Degruyter and Bonadonna, 2012].Satellite visibleinfrared radiometric observations from geostationary platforms are usually exploited for long-range trajectory tracking and for measuring low-level eruptions [e.g., Rose et al., 2000; Corradini et al., 2011]. Ground-based microwave radars represent an important tool to detect ash clouds [Harris and Rose, 1983; Lacasse et al., 2004; Marzano et al., 2006; Gouhier and Donnadieu, 2008; Schneider and Hoblitt, 2009; Marzano et al., 2010]. The possibility of monitoring in all weather conditions at a fairly high spacetime resolution is the major advantage of using ground-based scanning weather radar systems at S, $C$ and $X$ band [Marzano et al., 2013]. On the other 
hand, Ka band Doppler radar can provide a higher sensitivity to medium size particles [Madonna et al., 2010].

The physical-chemical properties of volcanic particles are modified during advection, and size sorting takes place due to aggregation, breaking and fallout [Sparks et al., 1997]. Multi-wavelengths lidars can be complementary systems useful to integrate the micron-sized particle measurement, especially if far from the volcanic vent [e.g., Ansmann et al., 1992]. Lidar techniques developed for aerosol particle detection and estimation can be properly adapted for the retrieval of ash clouds [Gesteiger et al., 2011; Martucci et al., 2012; Scollo et al., 2012].

Previous methodological studies investigated the possibility of using ground-based radar systems for the quantitative remote sensing of volcanic ash cloud [Marzano et al., 2006; 2010]. A volcanic ash radar retrieval (VARR) algorithm for single- and dual-polarization radar systems was proposed and applied to S-, C- and X- band weather radar data volumes [Marzano et al., 2013; Montopoli et al., 2014]. This forward and inverse model framework can be extended to include very fine particles and to ingest both Ka band radars and multi-wavelength lidars.

The paper is organized as follows. Sect. II illustrates the ground-based observations carried out at the Atmospheric Research Station (Ireland) on May 15, 2010, concerning the ash plume emitted by the Eyjafjallajökull volcano. Sect. III summarizes the results and discusses the outlooks. The Annex deals with ash microphysics, scattering and extinction models for microwave and near-infrared wavelengths.

\section{VACR COMBINED RETRIEVAL CASE STUDY}

In order to fully exploit the multi-sensor multi-wavelength polarimetric forward scattering model for ash cloud remote sensing purposes, we can apply a Bayesian metrics to combined radar-lidar data [Marzano et al., 2013]. This approach will be briefly illustrated before discussing the Eyjafjallajökull eruption case study with measurements taken from the Mace Head site on May 15, 2010.

The Mace Head Atmospheric Research Station supersite over the west of Ireland in Carna, County Galway, is an example of integrated measuring site [Martucci et al., 2012]. Ground-based remote sensing of cloud microphysics is performed using Ka-band Doppler cloud radar (MIRA36), a Jenoptik CHM15K lidar-ceilometer at $1024 \mathrm{~nm}$, and a RPG-HATPRO multi-channel microwave radiometer combined with the synergistic analysis scheme. The radar MIRA36 radar is a monostatic magnetron-based pulsed Ka-Band Doppler radar. Linearly polarized signal at $35.5 \mathrm{GHz}$ is transmitted, while co- and cross polarized signals are received simultaneously to detect Doppler spectra of the reflectivity and linear depolarization ratio. The radar is also equipped with a 3-D scanning unit even though it is usually zenith pointing with a vertical resolution up to $15 \mathrm{~m}$. Note that CHM15K data are available only up to $8000 \mathrm{~m}$ and its sensitivity is lower than multi-wavelength research lidar [e.g., Madonna et al., 2010]. However, our purpose is to show the potential and flexibility of the combined inversion methodology.

II.A Combined radar-lidar retrieval algorithm

Similarly to the volcanic ash radar retrieval (VARR) approach [Marzano et al., 2006], the Volcanic Ash Combined Retrieval (VACR) utilizes 2 steps: i) ash classification; ii) ash parameter estimation. Both steps are trained by the HAPESS forward polarimetric model, where particle distributions, density, and permittivity parameters are supposed to be constrained random variables within a Monte Carlo approach (see Annex for details and symbols).

Within the VACR technique, ash classification is performed by means of Maximum A Posteriori Probability (MAP) estimation criterion. The probability density function (PDF) of each ash class $\left(c_{i}\right)$, condi- 
tioned to the measurement vector $\mathrm{x}_{m}$, can be expressed by Bayes' theorem (Marzano et al., 2006). The MAP estimation of ash class $c_{i}$, corresponds to the maximization with respect to $c$ of the posterior PDF $p\left(c_{i} \mid x_{m}\right)$. Under the assumption of multivariate Gaussian PDFs, the previous maximization reduces to minimizing a quadratic distance $d\left(\mathrm{x}, c_{i}\right)$ with respect to $c_{i}$ :

$$
d\left(\mathbf{x}_{m}, c_{i}\right)=\left\{\begin{array}{l}
\left(\mathbf{x}_{m}-\mathbf{m}_{x i}\right)^{T} \mathbf{C}_{x i}^{-1}\left(\mathbf{x}_{m}-\mathbf{m}_{x i}\right)+ \\
+\ln \left[\operatorname{det}\left(\mathbf{C}_{x i}\right)\right]-2 \ln \left[p\left(c_{i}\right)\right]
\end{array}\right\}(1)
$$

where " $\mathrm{T}$ " is the matrix transpose, whereas $\mathrm{m}_{x i}$ and $\mathrm{C}_{x i}$ are the mean vector and covariance matrix, respectively, of the combined simulated vector $\mathrm{x}$ of the class $c_{i}$. The a priori probability $p\left(c_{i}\right)$ can be used to weight the different classes on the basis of ancillary information and/or data. Using HAPESS dataset, a regressive model can be used as a function of the class $c$ to estimate both ash concentration $C_{p}$ and numberweighted mean diameter $D_{n p}$ of the class $c i$. Using a log-linearized parametric model, it holds:

$$
\left\{\begin{array}{l}
\ln C_{p}{ }^{(c)}=m_{\ln C}{ }^{(c)}+\mathbf{C}_{\ln x} C_{\ln x x} \mathbf{C}^{-1}\left(\ln \mathbf{x}_{m}-\mathbf{m}_{\ln x}{ }^{(c)}\right) \\
\ln D_{n p}{ }^{(c)}=m_{\ln D}{ }^{(c)}+\mathbf{C}_{\ln x D} \mathbf{C}_{\ln x x}^{-1}\left(\ln \mathbf{x}_{m}-\mathbf{m}_{\ln x}{ }^{(c)}\right)
\end{array}\right.
$$

where $m_{\ln c}$ and $m_{\ln D}$ are the log-value averages of $C_{p}$ and $D_{n p}, C_{\ln x c}$ and $C_{\ln X x}$ are the log-value cross-covariance and auto-covariance matrices, whereas $\ln x_{m}$ and $m i n x$ are log-value measurement vector and its mean vector. In (2) the regression coefficient matrices are obtained assuming a zero-mean random noise due to instrumental and forward modeling uncertainties. As already done elsewhere for VARR [Marzano et al., 2010, 2012], a numerical analysis of the VACR retrieval uncertainty has been carried out using a synthetic simulated dataset in presence of noise. Using 4 combined observables (as later on in sect. 4.2), results show that: i) the particle correct classification, using (1), has an average probability higher than $95 \%$; ii) the regression root mean square error, using (2), is less than $25 \%$ with respect to the same parameter mean value. Of course, these scores degrade if the noise increases due to instrumental causes or data pre-processing errors (e.g., path attenuation correction).

\section{II.B Available data and VACR results}

The Eyjafjöll stratovolcano is located under the Eyjafjallajökull small glacier within the Icelandic east volcanic zone. The eruptions in 2010 lasted several weeks [Guðmundsson et al., 2010; Marzano et al., 2010]. Geostationary satellite observations from SEVIRI, combined with other sources, indicate that the Eyjafjallajökull volcanic cloud covered much of Ireland on May 15, 2010 [Guðmundsson et al., 2012]. The ash cloud was indeed detected at the Mace Head site as documented in [O'Dowd et al., 2012].

In order to apply the VACR algorithm, we have considered ground-based observations of the Eyjafjallajökull volcanic ash plume on May 15, 2010 at Mace Head, carried out with the MIRA36 Doppler cloud radar and CHM15K lidar ceilometer. The Mace Head combined radar-lidar system provided both measured Zhhm and Ldrm at Ka-band from MIRA36 and $\beta_{h h m}$ at NIR from CHM15K. Note that, being the lidar ceilometer system at single wavelength, $\alpha_{h h}$ is derived after inverting measured $\beta_{h h m}$ data through an inversion algorithm assuming a proper lidar ratio at $\lambda=1064 \mathrm{~nm}$ [Ferguson and Stephens, 1983; Martucci et al., 2012].

In order to apply VACR to Mace Head data, the combined measurement vector is set to $\mathrm{X}_{m}=\left[\mathrm{Z} h{ }_{h m}(36 \mathrm{GHz}) \quad \operatorname{Ldrm}(36 \mathrm{GHz}) \quad \beta_{h h m}(1024 \mu \mathrm{m})\right.$ $\left.\alpha_{\text {hhm }}(1024 \mu \mathrm{m})\right]^{\mathrm{T}}$ which can be reduced to radar-only and lidar-only special cases (see Annex). Based on a priori information, the number of particle classes can be optimized by merging sub-classes and selecting 
two low concentration classes (VC and SC) and three orientations (TO.2, OO, and PO). Being far from the volcano vent, we do not expect lapilli and the coarse particles over Ireland, so that only 2 dispersed classes (VA, FA) are considered here. In order to consider clouds located above the freezing level, we have assumed a mixed-phased refractive index with a balanced mixture of ash and ice (VAm and FAm). Finally, in a cold region, pure ice crystals (IC) and dry snow (DS) may be expected and their microphysical modeling are derived from Marzano et al. (2007). Spherical ash particles are also included for VA, FA, CA considering both ash and mixed-phase particles. This implies that the number of VACR classes has been set to 18 .

The Eyjafjallajökull volcanic ash plume over Mace Head, discussed here, is related to the observation of May 15, 2010 from 20:00 till 24:00 UTC. Measurements of MIRA36 and CHM15K have been aligned in time and spatially averaged in order to deal with the different sensor specifications. Their time series have been resampled to every $30 \mathrm{~s}$, whereas in the vertical direction both measurements have been averaged at 30-m resolution.

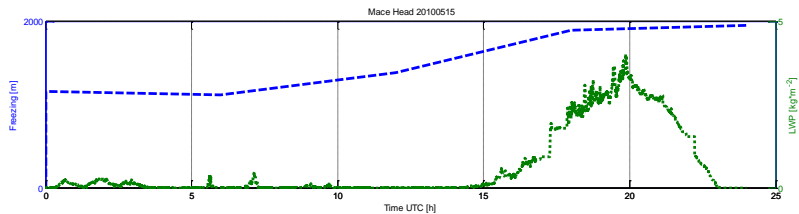

Figure 1: Time evolution of liquid water path (in $\mathrm{kg} / \mathrm{m}^{2}$ ), derived from HATPRO microwave radiometer, and freezing level during May 15, 2010.

The discrimination of ash clouds with respect to water clouds is still an open issue [Martucci et al., 2012]. The detection of a water cloud is aided by the liquid water path (LWP) estimate derived from collocated HATPRO microwave radiometer measurements. Fig. 1 shows the time series of LWP, together with the the freezing level height estimated from the temperature profile derived from HATPRO. Note that LWP is increasing up to $4 \mathrm{~kg} / \mathrm{m}^{2}$ from 15:00 till 22:00 being almost negligible after then, while the freezing level is below $2 \mathrm{~km}$. Colocated radar-lidar measurements are shown in Fig. 2 in terms of 24-hour profile time series of copular reflectivity $Z_{h h}$ and $L d r$ from MIRA36 and backscatter coefficient $\beta_{h h}$ from CHM15K.

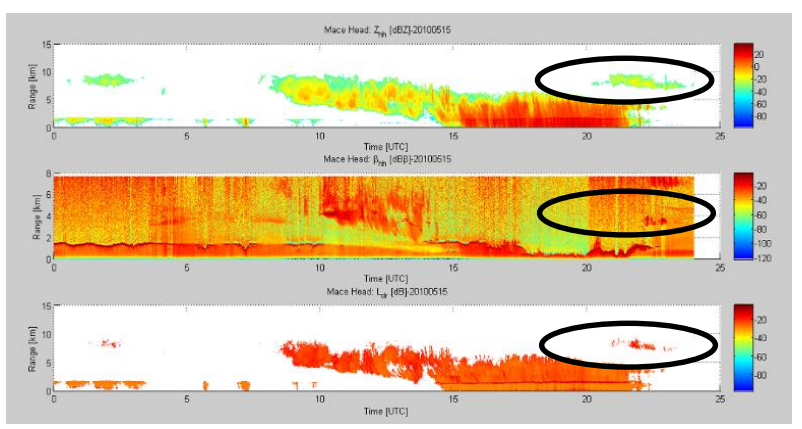

Figure 2: Range-time section of copolar reflectivity $\mathrm{Zhh}(36 \mathrm{GHz})$ and linear depolarization ratio $\mathrm{Ldr}(36 \mathrm{GHz})$ from MIRA36 (upper and lower panel) and copolar backscatter coefficient $\beta \mathrm{hh}(1064 \mathrm{~nm})$ from CHM15K (middle panel) on May 15, 2010. The black circles indicate the ash signature.
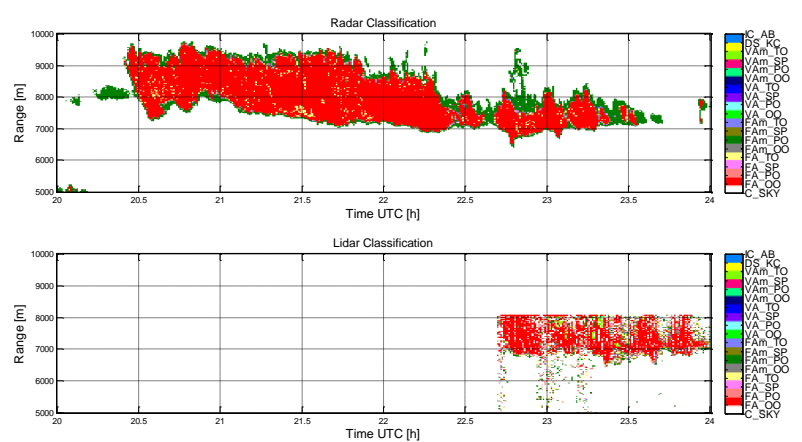

Figure 3: (Upper panel) Classification of ash cloud observed at Mace Head May 15 2010, from 20:00 to 24:00 UTC, using only the radar observables (Zhh and $L_{d r}$ ). (Lower panel) Same as upper panel, but using both radar and lidar observables ( $Z \mathrm{hh}, \mathrm{Ldr}$, $\left.\beta_{h h}, \alpha_{h h}\right)$, when available. Note lidar-ceilometer data are not available above $8000 \mathrm{~m}$.

The signature before 20:00 below $5 \mathrm{~km}$ can be attributed to an incoming altostratus which is followed 
by a stratus clouds with some rainfall. Between 20:00 and 22:00 the lower stratus is coexisting with a high cloud, as showed by the radar above $6 \mathrm{~km}$, which is not detected by CHM15K due to the stratus extinction. After 22:00, when the LWP gets almost negligible due to the dissipation of the lower stratus (see Fig. 1), the lidar-ceilometer signal shows a peak at some $8 \mathrm{~km}$. Correspondingly, the radar signal shows a feature around $8 \mathrm{~km}$, a bit weaker than before 22:00. In summary, the ash cloud lidar-radar combined signature can be clearly detected around $6.5-10 \mathrm{~km}$ between 20:00 and 24:00, as indicated by black ellipses in Fig.2.

Results from the two-step VACR are presented in Fig. 3, where the VACR classification is obtained through (1) by using radar and radar-lidar observables. Using (2), Fig. 4 shows the VACR estimate of ash concentration by employing only radar observables, only lidar observables, and combined radar-lidar observables.

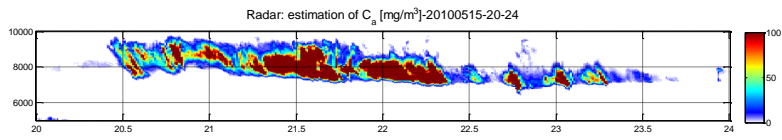

Lidar: estimation of $\mathrm{C}_{\mathrm{a}}\left[\mathrm{mg} / \mathrm{m}^{3}\right]-20100515-20-24$

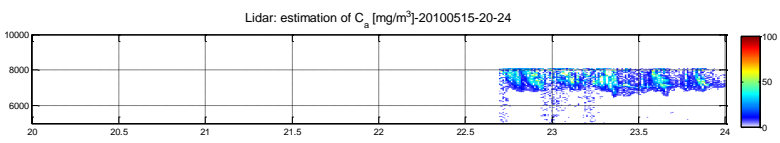

Radar \& Lidar: estimation of $\mathrm{C}_{\mathrm{a}}\left[\mathrm{mg} / \mathrm{m}^{\mathrm{3}} \mathrm{T}-20100515-20-24\right.$

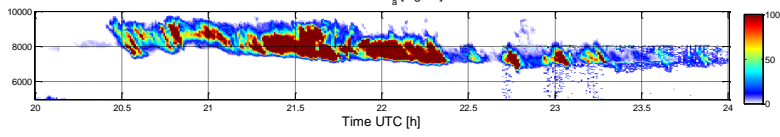

Figure 4: Estimation of ash concentration in the zoomed ash cloud region in Fig. 3, using radar (upper panel), lidar-ceilometer (middle panel) and combined lidar-radar observables, when available (lower panel).

Fig. 3 and 4 indicate that the prevailing ash classes are fine ash FA-OO (about 77\%) with FAm-PO (16\%) and some FA-PO, FA-TO, FA-SP (less than 4\%) and FAm-OO, FAm-TO, VAm-TO (less than 3\%). This means that oblate ash particles are coexisting with heterogeneous nucleation of ice crystals. Lidar signatures are sensitive to micron-sized particles and reveal the presence of mixed very fine ash VAm which are mainly detected at the upper edges of the ash cloud (notably after 22 UTC in Fig. 4).

From Fig. 4 it is interesting to note that estimated ash concentration in the middle of ash cloud can reach values of $100 \mathrm{mg} / \mathrm{m}^{3}$ and its vertical profile is far from being uniform. By vertically integrating the VACRbased estimates of ash concentration of Fig. 4, we can derive the ash cloud columnar content shown in Fig. 5. Similarly to Fig. 4, Fig. 6 shows the mean diameter of ash particles retrieved by VACR using (2). The combination of radar and lidar data extends the capability of each to detect ash particles between 20:00 and 24:00.

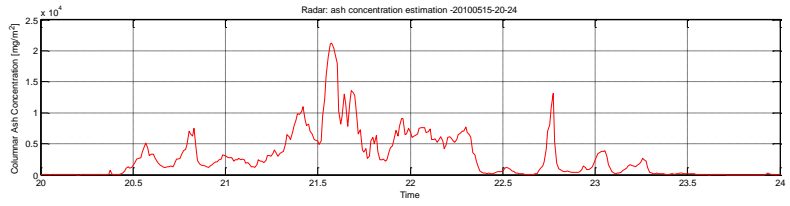

Figure 5: Columnar ash concentration derived from VACR algorithm by vertically integrating ash concentration derived from Fig. 4.

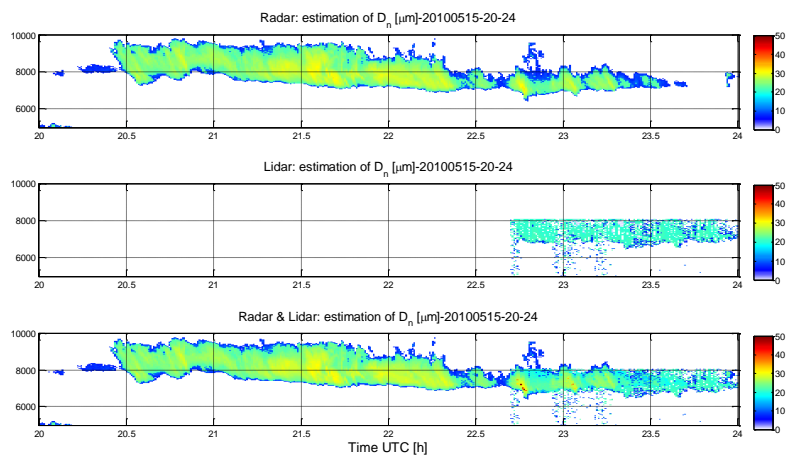

Figure 6: As in Fig. 4, but for particle mean diameter $D_{n}$.

Estimated effective diameters goes from 5 microns at the ash cloud edge and in regions where the cloud 
layer is thin (mainly detected by lidar) up to $40 \mathrm{mi}-$ crons in the cloud inner core (mainly detected by Kaband radar).

\section{CONCLUSIONS}

Microwave radars and multi-wavelength lidars are complementary instruments, providing a complementary view with respect to the satellite segment. This work has shown how dual-polarization groundbased weather radars and lidars can be merged for volcanic ash cloud dynamical monitoring and quantitative retrieval of ash category, concentration, and effective diameter. The expected accuracy of VACR algorithm is conditioned by the microphysical assumptions. The Eyjafjallajökull volcanic ash plume over the Mace Head site on May 15, 2010 has been used for testing the VACR methodology using a Kaband radar and NIR lidar-ceilometer. Results confirm the potential of the combined approach highlighting interesting features of the retrieved ash cloud in terms of concentration and mean diameters. Future work shall be focused on in situ data for a systematic characterization of the VACR absolute error estimates.

Acknowledgments. This work has been supported by the European FP7 projects APhoRISM (FP7-SPA2013, n. 606738) and FutureVolc (FP7-ENV-2012, n. 308377).

\section{REFERENCES}

[Ansmann et al. 2012] Ansmann, A., et al.. Combined Raman elastic-backscatter lidar for vertical profiling of moisture, aerosol extinction, backscatter and lidar ratio, Appl. Phys. B., 55, 18-28.

[Corradini et al., 2011] Corradini, S., et al. (2011). Volcanic Ash Cloud Properties: Comparison Between MODIS Satellite Retrievals and FALL3D Transport Model. IEEE GRSL, 8, 248-252.
[Degruyter and Bonadonna, 2012] Degruyter, W., and Bonadonna, C. (2012). Improving on mass flow rate estimates of volcanic eruptions, Geophysical Research Letters, 39, L16308.

[Gasteiger et al., 2011] Gasteiger, J., et al. (2011). Volcanic ash from Iceland over Munich: mass concentration retrieved from ground-based remote sensing measurements, ACP, 11, 2209-2223.

[Gouhier and Donnadieu, 2008] Gouhier, M., et al. (2008). Mass estimations of ejecta from Strombolian explosions by inversion of Doppler radar measurements. JGR, vol. 113, pp. B10 202-B10 219.

[Graf et al., 2007] Graf, H. F., et al. (2007). Volcanic effects on climate: revisiting the mechanisms, Atm. Chem. Phys., 7, 4503-4511.

[Guðmundsson et al., 2010] Guðmundsson, M. T., et al. (2010). Eruptions of Eyjafjallajökull Volcano, Iceland. EOS 91, 190-191.

[Harris and Rose, 1993] Harris, D. M, and Rose W. I. (1983). Estimating particle sizes, concentrations, and total mass of ash in volcanic clouds using weather radar, J. Geophys. Res., 88, C15, pp. 10969-10983.

[Lacasse et al., 2004] Lacasse, C., et al. (2004). Weather radar observations of the Hekla 2000 eruption cloud, Iceland, Bull. Vol., 66, 5, 457-473.

[Madonna et al., 2010] Madonna, F., et al. (2010). Observation of nonspherical ultragiant aerosol using a microwave radar, Geophys. Res. Lett., 37, L21814, doi:10.1029/2010GL044999.

[Marticci et al. 2012] Martucci, G., et al. (2012). Impact of volcanic ash plume aerosol on cloud microphysics. Atm. Environment, 48, 205-218.

[Marzano et al. 2006] Marzano, F. S., et al. (2006). Volcanic ash cloud retrieval by ground-based microwave weather radar. IEEE TGRS, 44, 3235-3246.

[Marzano et al. 2010] Marzano, F. S., et al. (2010). Monitoring sub-glacial volcanic eruption using Cband radar imagery. IEEE TGRS, 48, 1, 403-414. 
[Montopoli et al. 2014] Montopoli, M., et al. (2014) Interpretation of observed microwave signatures from ground dual polarization radar and space multi-frequency radiometer for the 2011 Grímsvötn volcanic eruption (2014), Atm. Meas. Techniques, 7 (2), pp. 537-552. doi: 10.5194/amt-7- 537-2014.

[Rose et al. 2000] Rose, W. I., et al. (2000). Integrating retrievals of volcanic cloud characteristics from satellite remote sensors: A summary, Phil. Trans. R. Soc. A, vol. 358, 1770, 1585-1606.

[Schneider and Hoblitt, 2012] Schneider, D. J., Hoblitt, R. P. (2012). Doppler weather radar observations of the 2009 eruption of Redoubt Volcano, Alaska, J. of Vol. and Geoth. Res. v. 259, p. 133-144.

[Scollo et al. 2012] Scollo, S., al. (2012). Monitoring Etna volcanic plumes using a scanning LiDAR. Bull Volcanol, DOI 10.1007/s00445-012-0669-y.

[Sparks et al. 1997] Sparks, R. S. J., et al. (1997). Volcanic plumes, Wiley, New York (USA). 